\title{
Initial assessment of reuse of sustainable wastes for fibreboard production: the case of waste paper and water hyacinth
}

\author{
E. O. Ojo ${ }^{1,5}$ (I) $\cdot$ M. Okwu ${ }^{2} \cdot$ L. Edomwonyi-Otu ${ }^{3} \cdot$ F. A. Oyawale ${ }^{4}$
}

Received: 4 February 2019 / Accepted: 9 May 2019 / Published online: 20 May 2019

(c) The Author(s) 2019

\begin{abstract}
In this early study, new cement-bonded bi-composite fibreboard (FB) was made from water hyacinth (WaHy) and waste paper (WP). Ordinary Portland cement (PdCe) used as a binder was mixed with other two additives: gypsum plasters (GyPl) and wood ash (WdAh), in defined proportions to form bonding matrices. The WP and WaHy were pre-treated and a linked process was developed for the mixing and consolidation steps. The FBs produced were based on different proportions of composites, binder, and additives mixed. The FBs produced were made from different proportions of composites, binders, and additives. Improved tensile strength was observed for bi-composite FB from WaHy mixed with WP. In general, FBs having densities in the range of $0.50-0.57 \mathrm{~g} \mathrm{~cm}^{-3}$ were compared favourably with the ASTM and ANSI standards (95\%), thus making the FBs a potential alternative for building and construction purposes. More elaborate research with advanced analytical techniques is hereby suggested.
\end{abstract}

Keywords Fibreboard · Office waste paper $\cdot$ Water hyacinth $\cdot$ Sustainable $\cdot$ Waste management $\cdot$ Mechanical property

$\begin{array}{ll}\text { Abbreviations } \\ \text { FB } & \text { Fibreboard } \\ \text { GyPl } & \text { Gypsum plaster } \\ \text { PdCe } & \text { Portland cement } \\ \text { WaHy } & \text { Water hyacinth } \\ \text { WdAh } & \text { Wood ash } \\ \text { WP } & \text { Waste paper }\end{array}$

$\triangle$ E. O. Ojo

ebenezer.ojo@strath.ac.uk

1 Faculty of Science and Engineering, Osun State University, PMB 4494, Osogbo, Nigeria

2 Department of Mechanical Engineering, Federal University of Petroleum Resources, PMB 1221, Effurun, Delta State, Nigeria

3 Department of Chemical Engineering, Ahmadu Bello University, PMB 1013, Zaria, Kaduna State, Nigeria

4 Department of Mechanical Engineering, Faculty of Engineering, Covenant University, KM 10, Canaan Land, Ota, Nigeria

5 Present Address: Strathclyde Institute of Pharmacy and Biomedical Sciences, University of Strathclyde, Glasgow G1 1RD, UK

\section{Introduction}

Fibreboard (FB) is a widely adopted wood-based insulation material used in the building and construction industry. Depending on the application, the particular FB product may vary from the medium-density (MDF) to high-density fibreboard (or hardboard) [1]. The consumption of MDF in Europe in 2012 was reported as 10.3 million $\mathrm{m}^{3}$ ("European Panel Federation (EPF)," 2014). It is now important to intensify studies on developing processes for utilisation of different low-cost, sustainable, and renewable sources of potential lignocellulosic composites obtained from municipal waste and by doing so minimising deforestation and enhancing waste management [2]. Lignocellulosic biomass is primarily made up of lignin and cellulosic compounds and is majorly obtained from natural wood and plant origins [3]. Lignocellulosic materials or biomass make up the largest percentage of waste generated globally. Industrial activities such as building and construction, pulp and paper, and agro-allied based (food and cash crops) have contributed largely to lignocellulosic waste which ends up in the landfills or burned with emissions of methane and carbon dioxide contributing to greenhouse gases.

Agro-forestry wastes such as rice straw, wheat straw, bagasse, sawdust, water hyacinth, oil palm, hazelnuts, and other fibrous dry leaf are now considered alongside with 
the recycled woody materials from construction sites for fibreboard production [3-10]. The use of renewable plant sources as alternative composites was based on the mechanical and physical properties obtainable. The use of cellulosic fibres as composites has been reported to lower thermal conductivity in buildings, minimise shrinkages, and enhance internal absorption of acoustic sound plus the dissipation of structure-borne vibrations [11]. However, the properties produced depend on the lignocellulosic biomass, binders, water, additives, and the production process (dry or wet manufacturing process).

For the production of FB, cementitious materials such as ordinary Portland cement (PdCe) from limestone clinkers [2, $8,9]$, fly ash, ground granulated blast furnace ash, gypsum [12], urea/phenol formaldehyde, polymeric diphenylmethane di-isocyanate (MDI) have been used exclusively for binding straw particles $[4,13]$, and silica fumes have been used as adhesives. The binders could be added individually or mixed at a determined ratio to achieve specific physical, mechanical, and surface properties of interest. Also, the addition of water acts as a catalyst and other additives such as calcium chloride monohydrate $\left(\mathrm{CaCl} \bullet \mathrm{H}_{2} \mathrm{O}\right)$, polypropylene, and maleic anhydride may be added if required [9, 14, 15]. For this study, water hyacinth plant and waste paper (WP) made from woody biomass were used as composites for the production of medium-density fibreboard. To date, reports on the utilisation of waste paper (WP) and water hyacinth (WaHy) are minimal [16].

WaHy otherwise known as Eichhornia crassipes has been classified as a problematic wild plant on water bodies. It has been investigated for its use as a sustainable resource for bioremediation of waste and industry effluents, production of paper, briquette, compost, fodder, animal feed, and also for bioprocessing of biofuel and platform chemicals through saccharification and fermentation processes [7, 17-19]. Based on the historical development and spread of water hyacinth from its host country, WaHy is now known as the world's fastest-growing water-borne weed, with biomass doubling capacity in 14 days. It meshes together to form thick floating mats that make water navigation, fishing, and irrigation near impossible.

In essence, water hyacinth is considered a potential threat to the environment and economics of many countries. The plant reproduces vegetatively and by seeds. The plant also produces masses of seed that can lie dormant for up to 15 years, a potential ability to reproduce sustainably. If well managed for sustainable production of value-added products such as fibreboard, it could generate economic advantages. Also, the use of WP as a composite for FB production offers the advantage of minimising the municipal solid waste load [20]. While the recycling technology for paper is already in place [21], some recovered WPs are now being processed for bioethanol production and other bio-based chemicals
[22-26], among other uses. In a similar way to water hyacinth, channelling WP into the production of more valueadded products would provide increased economic advantages and minimise carbon footprints.

The study aims to investigate the production of cementbonded FB combining pre-treated WaHy and waste office paper as composites. Methods' development for the pretreatment of the fresh WaHy stalks and waste office papers was studied. It thus requires low-cost design and fabrication of a mixer and screw press for reproducible FB production. A one-factor-at-a-time (OFAT) approach was used to investigate the effect of mixing ratios of the composites and binder concentrations. Standard physical and mechanical tests were performed to ascertain the suitability of the fibre produced in comparison with the established global standards for its use for building and construction industry. Optimisation of the composites binder matrix is not intended to be covered in this work. However, a detailed study using the design of experiment approach to determine optimum mix will be included in our subsequent studies.

\section{Materials and methods}

\section{Materials}

Two types of composite materials were used in this study for the FB production: white office WP and water hyacinth (WaHy). The WP was sourced from the waste paper generated from offices and at the printing press of Ladoke Akintola University of Technology (LAUTECH), Ogbomoso, and WaHy from Awba dam at the University of Ibadan (UI), Nigeria. Micronisation of WP was carried out using a method previously developed by [27]. In the method, a combined two-stage wet and dry milling process was adopted. The wet step de-fibred the paper by soaking in water to form paper mash and subsequently dried. The oven-dried mashed paper balls were then micronised during the dry step and sieved using BSS 36 mesh size (equivalent to $420 \mu \mathrm{m}$ ) (Endecot, UK). The water hyacinth was collected, and the fibrous stems were cut into smaller pieces of varying length between 2 and $6 \mathrm{~cm}$ for easy handling prior to comminution. The cut pieces were air-dried for $8 \mathrm{~h} /$ day for 10 days at an average daily peak temperature of $30-32{ }^{\circ} \mathrm{C}\left( \pm 2{ }^{\circ} \mathrm{C}\right)$ measured using a thermometer. PdCe (Lafarge Cement, Ewekoro) was used as a cementitious binder and mixed in proportions with two other additives: gypsum plaster (GyPl) (Lagos, Nigeria) and wood ash (WdAh) obtained from LAUTECH bakery. The collected WdAh was sieved using the BSS 18 mesh size (equivalent to $850 \mu \mathrm{m}$ ) and air-dried for $4 \mathrm{~h}$ to reduce the moisture content. The binder and additives were stored in a non-humid environment at ambient temperature $\left(\sim 28^{\circ} \mathrm{C}\right)$. 


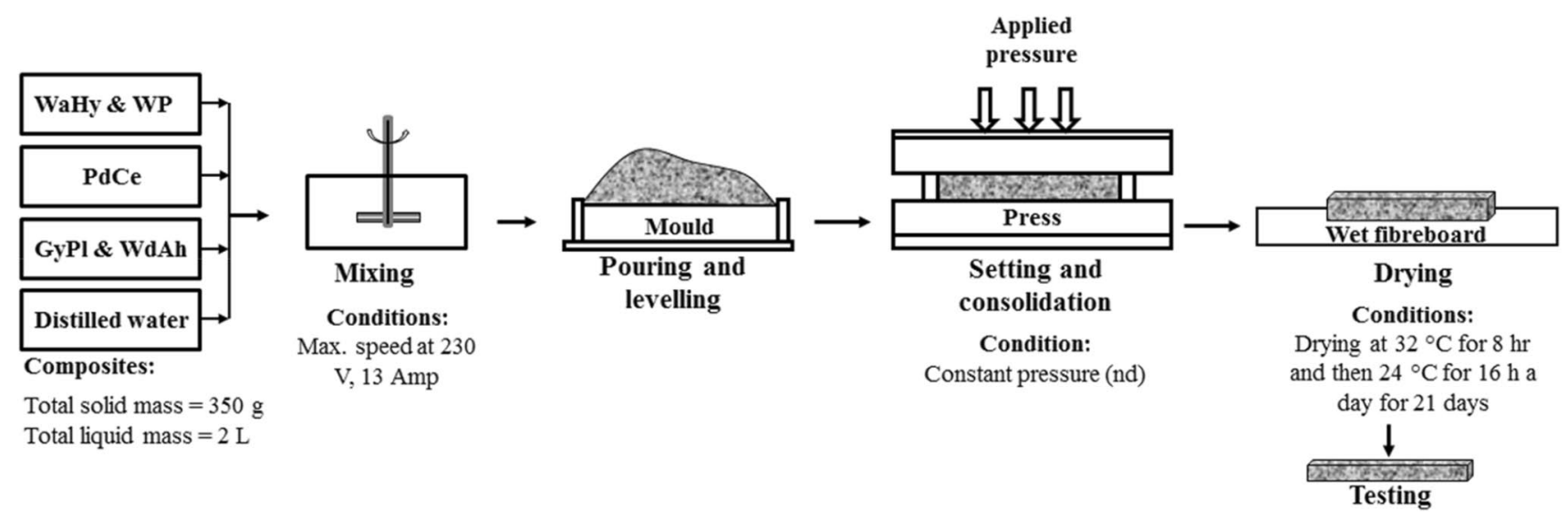

Fig. 1 Schematics of fibreboard production process [from material mixing (LHS) to the final fibre product and testing (RHS)])

Table 1 Mix proportions of fibreboard composites to the suitability of WaHy and WP for FB production

\begin{tabular}{|c|c|c|c|c|c|}
\hline \multicolumn{2}{|c|}{ Reinforcement (g) } & \multirow{2}{*}{$\begin{array}{l}\text { Binder }(\mathrm{g}) \\
\text { PdCe }\end{array}$} & \multicolumn{2}{|c|}{ Additives (g) } & \multirow{2}{*}{$\begin{array}{l}\text { Liquid (L) } \\
\text { Water }\end{array}$} \\
\hline WaHy & WP & & WdAh & GyPl & \\
\hline 200 & 0 & 50 & 50 & 50 & 2 \\
\hline 100 & 100 & 50 & 50 & 50 & 2 \\
\hline 0 & 200 & 50 & 50 & 50 & 2 \\
\hline
\end{tabular}

\section{Experimental procedures}

A simple OFAT approach was adopted to study the suitability of the composite materials for FB and also to investigate the effect of varying the percentage compositions of binder and additives in each formulation on the properties of the FB formed. The fibreboard production process is as shown in Fig. 1. Before FB production, the composites were mixed with $\mathrm{PdCe}$ and other additives at the designed proportions, as summarised in Tables 1 and 2. The micronised WP added to WaHy was based on $\% \mathrm{w} \mathrm{w}^{-1}$. In all the experiments,
$200 \mathrm{~g}$ of composite materials was used per sample and $2 \mathrm{~L}$ of water was added to act as a catalyst during mixing. The moisture contents of composites were assumed negligible. Concentration matrix for composite materials, binder and additives was varied and their impact on the mechanical properties of the fibreboard was investigated. In the first study (Table 1), the various proportions of composites at a constant amount of binder and additives were intended to ascertain the effect of composites on the properties of FB produced. Similarly, study two (Table $2 \mathrm{a}-\mathrm{c}$ ) investigates the effect of binder and additives mix on the FB strength at constant composites mix ratios.

FB was made by adding different proportions of composites, binder, additives, and $2 \mathrm{~L}$ of distilled water using an electrically operated mixer as indicated in Tables 1 and 2 . The prototype $1 \mathrm{hp}$ electrical motor mixer fabricated at the Chemical Engineering Department Workshop, University of Lagos (UNILAG) was operated at the maximum speed for $30 \mathrm{~min}$ for each sample. Compaction was carried out using a prototype fabricated screw press with a mould (Mechanical Workshop, UI, Ibadan). The mould geometry presets the

Table 2 Experimental design to investigate the effect of different concentrations of binder and additives on physical and mechanical properties of fibreboard produced from lingocellulosic composites

\begin{tabular}{|c|c|c|c|c|c|c|c|c|}
\hline \multicolumn{3}{|c|}{ Constant parameters } & \multicolumn{2}{|l|}{ Study 1} & \multicolumn{2}{|l|}{ Study 2} & \multicolumn{2}{|l|}{ Study 3} \\
\hline \multicolumn{2}{|c|}{ Reinforcement (g) } & \multirow{2}{*}{$\begin{array}{l}\text { Liquid (L) } \\
\text { Water }\end{array}$} & \multirow{2}{*}{$\begin{array}{l}\text { Binder }(\mathrm{g}) \\
\mathrm{PdCe}\end{array}$} & \multirow{2}{*}{$\begin{array}{l}\text { Additive } 1 \text { (g) } \\
\text { WdAh }\end{array}$} & \multirow{2}{*}{$\begin{array}{l}\text { Binder }(\mathrm{g}) \\
\mathrm{PdCe}\end{array}$} & \multirow{2}{*}{$\begin{array}{l}\text { Additive } 2 \text { (g) } \\
\text { GyPl }\end{array}$} & \multirow{2}{*}{$\begin{array}{l}\text { Additive } 1 \text { (g) } \\
\text { WdAh }\end{array}$} & \multirow{2}{*}{$\begin{array}{l}\text { Additive } 2(\mathrm{~g}) \\
\text { GyPl }\end{array}$} \\
\hline WaHy & WP & & & & & & & \\
\hline 100 & 100 & 2 & 150 & 0 & 150 & 0 & 150 & 0 \\
\hline 100 & 100 & 2 & 100 & 50 & 100 & 50 & 100 & 50 \\
\hline 100 & 100 & 2 & 75 & 75 & 75 & 75 & 75 & 75 \\
\hline 100 & 100 & 2 & 50 & 100 & 50 & 100 & 50 & 100 \\
\hline 100 & 100 & 2 & 0 & 150 & 0 & 150 & 0 & 150 \\
\hline
\end{tabular}

Constant parameters column is associated with each of the study groups separately. A total of three mix proportions of composites are investigated 
shape of the insulation boards formed to a predetermined thickness. Consistent compaction pressure for all prepared samples was ensured by keeping a constant lower lock position for the press, a point at which further screwing of the press is practically impossible.

\section{Equipment design and fabrication}

The designed and fabricated low-cost prototype electrically operated mixer shown in Fig. 2a has a stirring rod and Rushton-type impellers attached at the lower end of the stirring rod. The mixing operation was performed by running the $1 \mathrm{hp}$ motor at the highest speed $(1800 \mathrm{rpm})$ due to the poor flowability of the mixture, the mixing continued until a homogenous mixture was achieved. Approximately three cycles of $10 \mathrm{~min}$ mixing were adopted. The screw press mould consists of a metallic casing ( $2 \mathrm{~mm}$ thick) with the dimension of $300 \times 300 \times 100 \mathrm{~mm}$ and the top compression plate $290 \times 290 \mathrm{~mm}$, as shown in Fig. $2 \mathrm{~b}$. The shaft holds the compression plate firm to the metallic casing. The metallic box was made from $2 \mathrm{~mm}$-thick metal sheets. The composite materials (WdAh, WP, GyPl, PdCe, and water) mixed mechanically were transferred into the metallic mould, spread and levelled in the box. The compression plate was placed on the screw press (mould) to cover the wet homogenous composite mixtures. The screw press was turned until the press has exacted firm pressure (as the pressure exerted could not be experimentally determined, a uniform screw position was maintained for the fibreboard) on the levelled mixtures and it was allowed to stay for $5 \mathrm{~min}$ for compaction and water drainage. To ensure consistency, same screw position was maintained for all the experiments. The

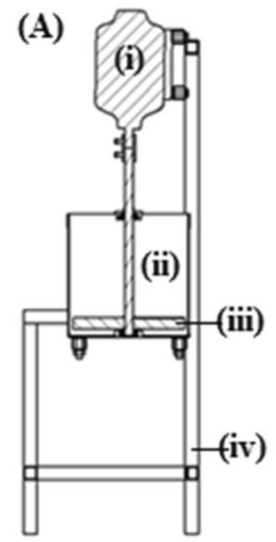

(B)

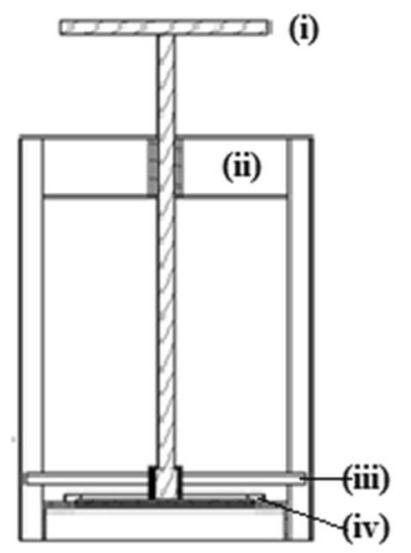

Fig. 2 Engineering design and fabrication of prototype a electrically operated mixer and $\mathbf{b}$ mechanically driven screw press used for the production of the fibreboard. For A, (i) $1 \mathrm{hp}$ electrical work, (ii) mixing volume, (iii) Rushton-type impeller and (vi) mixer frame B, (i) screw hand, (ii) rigid frame body, (iii) lower lock system and (iv) compaction plate screwed press was released after $5 \mathrm{~min}$ and the compressed fibreboard was removed and carefully dislodged from the mould. The fibreboard was allowed to set by air-drying at an ambient temperature of $32{ }^{\circ} \mathrm{C}$ for $8 \mathrm{~h}(9 \mathrm{am}-5 \mathrm{pm}$ daytime sunshine) and $24{ }^{\circ} \mathrm{C}$ (ambient room temperature) for $16 \mathrm{~h}$, respectively, over a period of 5 days.

\section{Physical tests}

Visual inspections of the FBs were initially performed and the surface smoothness was checked. To determine the FB densities, the physical dimensions and mass of the test samples were taken and the density was calculated. To determine the thickness swelling, the FB formed was submerged in distilled water for $24 \mathrm{~h}$ at an ambient temperature of $24{ }^{\circ} \mathrm{C}$. The percentage increase in thickness for each test samples was after that determined using Eq. 1.

Thickness swelling $(\%)=\left[\frac{T_{\mathrm{w}}-T_{\mathrm{i}}}{T_{\mathrm{i}}}\right] \times 100$,

where $T_{\mathrm{i}}$ and $T_{\mathrm{w}}$ were fibreboard thickness when dry and wet, respectively.

Similarly, the percentage of water absorbed was determined using the Eq. 2:

Water absorptivity $(\%)=\left(\frac{W_{\mathrm{w}}-W_{\mathrm{i}}}{W_{\mathrm{i}}}\right) \times 100$,

where initial weight $W_{\mathrm{i}}$ was the measured weight of the dried sample and $W_{\mathrm{w}}$ was the wet weight after submerging in water for $24 \mathrm{~h}$. Another factor considered when evaluating the fibreboard suitability is its ability to hold nails, especially when they are subjected to load under gravity. A nail-head pull through the test is commonly used to assess this property. The FB produced was subjected to tensile stress and compressive strength tests. Test samples were prepared by cutting the samples into 30 -by- $60 \mathrm{~mm}$ for the tensile stress test, however, for compression test, samples were cut in a square dimension of 100 by $100 \mathrm{~mm}$ having $\pm 0.5 \mathrm{~mm}$ tolerance. Two test samples were prepared for each FB and the average values were recorded. The mechanical testing machine (Universal Instron, Buckinghamshire, UK) was automated and the corresponding value of forces and stresses at peak and break point of the samples was recorded.

\section{Results and discussion}

\section{Composite pre-treatment, process development, and equipment design}

The properties of the cement-bonded FB produced depend largely on the linked operational steps that make up the 
manufacturing process. Figure 1 shows the schematic of linked process steps starting with the composites, binders, and other additives required for the FB production. Of particular interest is the processing of the wet stalks of the WaHy and WP. It is important to note that the composites pre-treatment steps resulted in fibres with the right properties. Depending on the source of the composite, WP and WaHy can be classified as wood and non-wood fibres, respectively. The WP is often obtained from a wood source by pulping [3] process but the pulps could also be available from non-wood sources [28]. Micronisation of the WP to produce microfibres increases the available surface area for cellulosic fibre interaction. It also increases lignin matrix potential for binding on reaction with water [29], thus enhancing the mechanical properties of the composites in addition to the binder and additive activity. The micronisation steps, involving wetting and drying cycle hornify the fibres thus improving dimensional stability and reducing water retention capacity [30, 31]. FBs with a higher proportion of WP result in increased density, reduced voids, and low water absorptivity. In recent times, cellulosic fibres have been processed for self-binding property that disallows the use of binders either as nanofibres [32,33] or microfibrillated lignocellulosic pulp [34].

While the final particle size distribution (PSD) of WP microfibre is in the range $20 \leq x \leq 450 \mu \mathrm{m}$, the final WaHy pre-treated fibres were up to $2 \mathrm{~cm}$ long and less than $1 \mathrm{~cm}$ in diameter. The increased PSD for the WaHy was intended to provide a solid reaction surface for the binder and additives in addition to the microfibres as co-composite. Strips of composites have been known to improve the FB flexural and tensile stress to bending forces [35]. Combination of the WP microfibre and WaHy fibre strips is expected to enhance some unique properties such as improved surface appearances, better nail-withdrawal strength, and acceptable density as a medium-density FB. The mixing proportions for the FB produced are described in Tables 1 and 2.

The designed prototype laboratory-scale mixer shown in Fig. 2a achieved homogenous composites mixture. As this was a low-cost design intended for investigative purposes, mixing rate achieved was a fixed maximum at the highest rotating power of the $1 \mathrm{hp}$ electrical motor used (i.e., $1800 \mathrm{rpm})$. While the mixing hydrodynamics could not be studied here, a Rushton-type impeller was used to generate maximum mixing impact. While air occlusion during mixing could not be quantified due to less automation on the mixer (Fig. 2a), it is expected that this will not affect the compaction pressure, as the fibres from waste materials are micronized thus providing a larger surface area for binding with fewer voids. Further investigations would be suggested to optimise the mixing dynamics as the composite homogeneity may significantly impact on the uniformity of properties across the FB. The composite was gently stroked for initial compaction and the mould was transferred to the screw press.

The manually operated screw press shown in Fig. $2 b$ compressed the composites as the threaded rod is turned under pressure (schematics as shown in Fig. 1). The use of a lower lock to ensure compaction pressure consistency was adopted, as the means of direct quantification, was not included in the prototype design. A further measure taken was to ensure the same amount of materials was measured for all the sample tests in mass basis. As a qualitative measure, the lower lock position enables adequate compaction and liquid drainage. The liquid released by the composites as the voids collapsed under compressive force was drained through the tiny holes on the base of the mould. Additional 5 min setting and consolidation under the compressive force results in complete drainage of the liquid present in the cake and allows board firmness. The additional time allows the composites microfibers (with the large surface area) to initiate the formation of linkages with the binder (i.e., the calcium silicate based cement) and additives before drying started. The hydraulic properties of the cement to set in the presence of water meant systematic drying of the wet fibreboard. Contrary to curing method used for concrete and aggregates mix, first $8 \mathrm{~h}$ of drying at $32^{\circ} \mathrm{C}$, then followed by mild drying at ambient temperature $\left(\sim 24^{\circ} \mathrm{C}\right)$ for $16 \mathrm{~h}$ over 21 days. The overall approach resulted in non-cracked wellformed FB plates for the mixture tested. While the actual images of plates captured are not included, the quantitative assessments are presented.

However, considerations for the development of a lowcost and energy-efficient industrial-scale FB production process using sustainable waste materials are now underway. In contrast to the conventional production processes [1], the linked techniques described here could be scaled and more rigorous automation is incorporated. The automation will allow more detailed quantitative assessments of each operation units and evaluate overall impact on FB formed using only water as a binding catalyst and thus making the entire process eco-friendly.

\section{Re-useable wastes as composites for fibreboard production}

The use of multi-composite fibre materials for FB production has been reported [4, 15, 36, 37], and this study investigated the combination of woody and non-woody renewable and sustainable waste fibre sources to produce bi-composite FB. As shown in Table 1, a simple approach of mixing equal amount of binder and additives was adopted for a start. The evaluated effects of individual and combined composites mix on the physical and mechanical properties of the FB are as shown in Fig. 3. A non-significant decrease was observed for the FB density (from 0.499 to $0.470 \mathrm{~g} \mathrm{~cm}^{-3}$ ) 

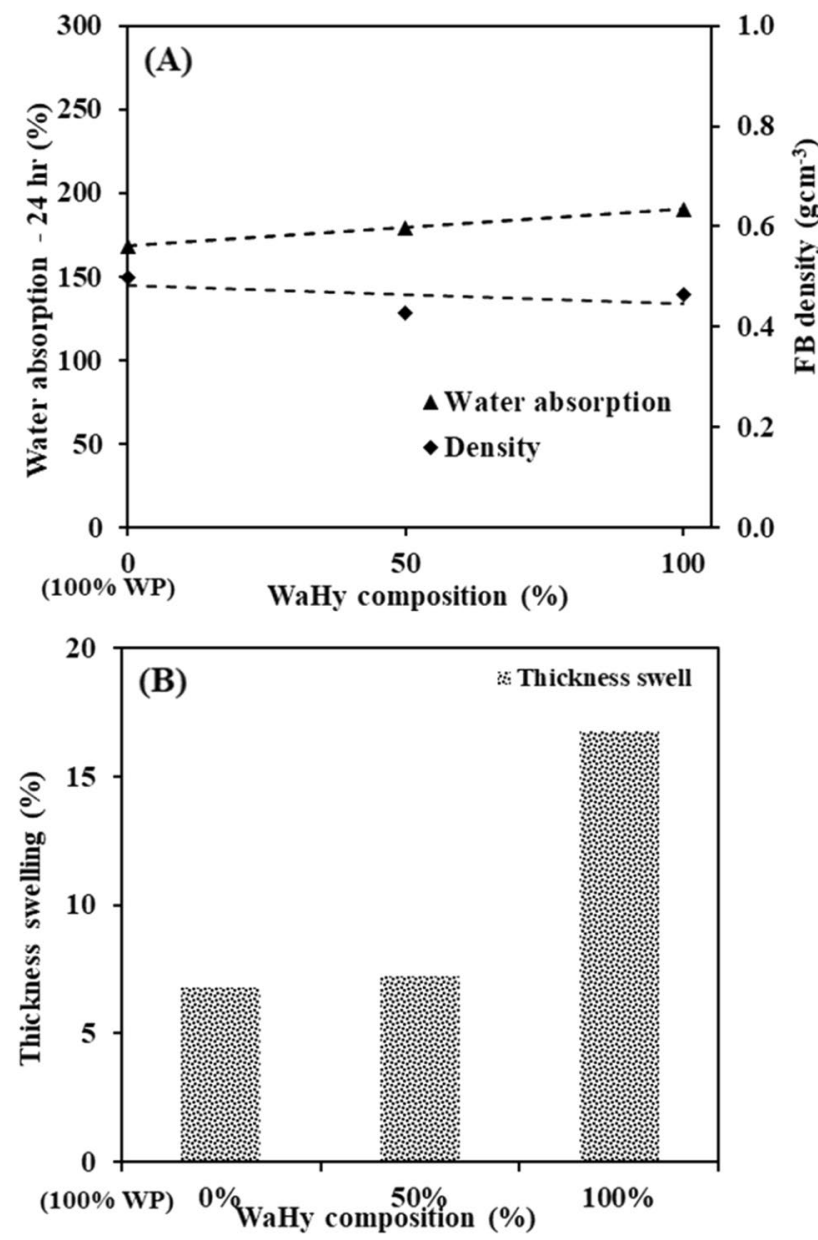

Fig. 3 Effect of mixed proportion of WaHy and WP on the physical properties such as: a percentage water absorption after $24 \mathrm{~h}$ and density and $\mathbf{b}$ percentage thickness swell of the fibreboard produced. The horizontal axis represents the WaHy percentage in the WaHy-WP mixtures e.g. 0\% WaHy has 100\% WP added. Binder and additives added in equal ratio. Each data points represent three averaged results of tested material

as the percentage composition of WaHy increases. Hypothetically, a higher FB density was expected for the $100 \%$ WP FB due to the large surface area-to-volume ratio of the micronised fibres compared to WaHy. Notwithstanding, the comparable FB densities suggest good mixing and adequate compaction pressure applied during the production.

The density values reflected an average density expected for WP-FB composite as previously reported (Fig. 3a). A study carried out by [15] reported FB densities in the range of $0.50-0.57 \mathrm{~g} \mathrm{~cm}^{-3}$ for different types of WP composites treated with varying levels of resin. A similar density value was obtained for a bi-composite FB produced by [21]. A decrease in wood-crete density from 0.713 to $0.473 \mathrm{~g} \mathrm{~cm}^{-3}$ was obtained as percentage WP by weight of sawdust increases from 10 to $75 \%$ in the composites, respectively. These show that the WP-based FB has potentials of

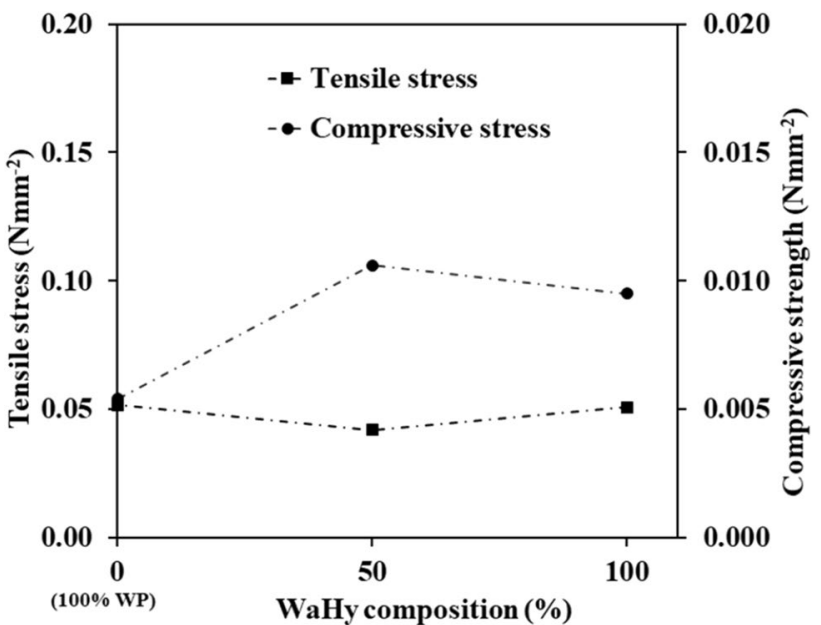

Fig. 4 Effect of mixed proportion of WaHy and WP on the mechanical properties such as tensile stress and compressive strength of the fibreboard produced. The horizontal axis represents the WaHy percentage in the WaHy-WP mixtures e.g., 0\% WaHy has $100 \%$ WP added

increased strengths and abilities to withstand sudden impacts due to increased density.

For absorption test, after $24 \mathrm{~h}$ of submerging in water, the percentage water absorbed increased slightly with an increase in the percentage of WaHy present in the bi-composite FB. The consideration for the bio-physicochemical properties of the WaHy will favour water absorption, which subsequently affects the binder and additives efficiency over a long exposure to water. Also, worth noting is the possibility of the calcium silicate-based PdCe and ash to form hydrates. As the fibres absorb and retain water molecules, the hydrate formation continues over time thus weakening the binding forces, which also increases the void rate at which voids are formed. The overall impact on the thickness swelling as shown in Fig. $3 \mathrm{~b}$ resulted in the significant rise for $100 \%$ WaHy composite when compared to $100 \% \mathrm{WP}$ and the equally mixed WP and WaHy. This remarkable observation means more investigative studies need to be undertaken on the suitability of WaHy as a sole composite for fibreboard production and understand the interaction between the composites fibres and the effect of additives.

Tensile stress and compressive strength of the FBs were also measured as shown in Fig. 4. No significant change in tensile stress was observed as the percentage of WaHy increased. The observation indicates that FB transition from elastic to plastic deformation under tensile force is independent of the fibre compositions or type but rather dependent on the binder used. Compressive strength, on the other hand, was significantly low for $100 \%$ WP but increases with increasing percentage of WaHy. The equally mixed composites were not significantly different from $100 \%$ WaHy. However, it indicates a threshold where compressive strength 
does not change with increasing addition of WaHy. Since the WP has a larger surface area to interact with the binder (PdCe), it is expected that the FB formed will be less ductile under compressive force as compared to $100 \% \mathrm{WaHy}$. The doubled compressive required to achieve deformation under compressive force is worth noting.

\section{Binder and additives' effect on FB physical properties}

Understanding the effect of the binder (PdCe) and additives ( $\mathrm{GyPl}$ and $\mathrm{WdAh}$ ) is very crucial and the mixing ratio is as shown in Table 2. The result shown in Fig. 5a for FB density indicates improved FB density as the ratio of PdCe to additives increases. FB density increased significantly up to $66.67 \%$ PdCe in the composite and then declined slightly when no additive was added to the binder. The density is within comparable ranges for all samples. In general, the use of WdAh and GyPl behaved similarly on the density of FB formed when added to PdCe. This again suggests PdCe as critical to achieving high-density FB because the denser the fibreboard, the better the mechanical properties. Comparison of Fig. 5a with Fig. 4a shows that the micronised WP and PdCe influence FB density more.

A general trend was also observed for the water absorption test as shown in Fig. 5b. The water absorption for WdAh is higher compared to $\mathrm{GyPl}$ and reduces from 246 to $172 \%$ as the percentage proportion of PdCe increases to $100 \%$. Notable is the rate of decline for $\mathrm{WdAh}$, showing $\mathrm{WdAh}$ as a weak additive for fibreboard production as it compromises its resilience to prolonged exposure to water or other liquid if used for construction purposes, except when laminated. The thickness swell shows similar trends as observed for the water absorption (Fig. 5c). Thickness swelling for PdCe supplemented with WdAh decreased with increase in percentage of PdCe, meanwhile, at increased GyPl, thickness swelling is not significantly different but higher when compared with increased PdCe. Comparing the three properties tested (Fig. 5a-c), 100:50 binder-to-additives mix ratio produced FB with the best properties. Also, as the density increased, water absorption reduced, and it correlated with reduced thickness swell. A similar trend was also reported by [8]. Comparison of Fig. 5c with Fig. 3b suggests the use of $100 \%$ WaHy with WdAh as the sole binder should be avoided.

\section{Binder and additives' effect on FB mechanical properties}

Tensile and compressive tests were carried out to study the effect of binder and additives mix on the properties of the FB produced. The WP and WaHy were added in equal proportion, and the amount was kept constant for all samples. For the bi-composite mixture, tensile stress increased as the
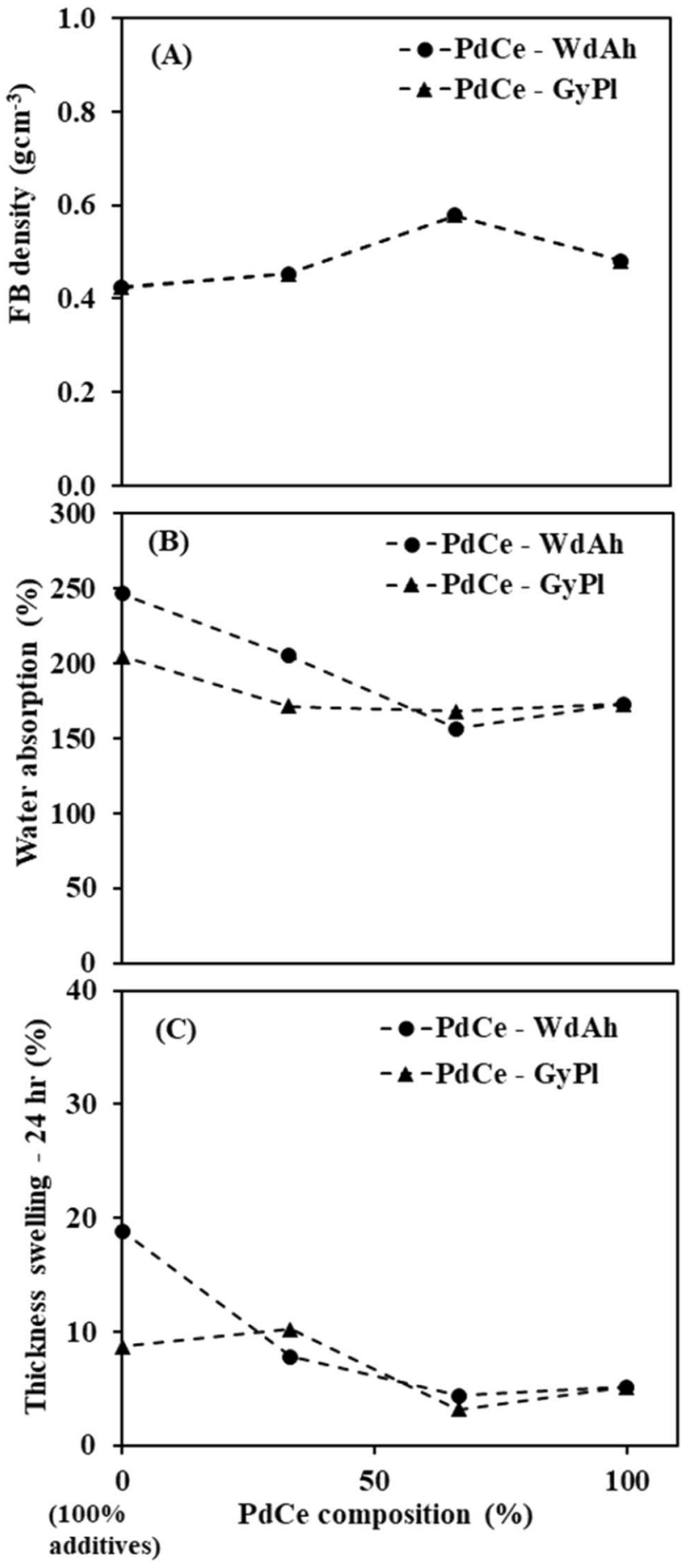

Fig. 5 Effect of mixed proportion of PdCe as a binder and WdAh/ $\mathrm{GyPl}$ as additives on the physical properties of a fibreboard produced from equal amount of WaHy and WP. a FB density, b percentage of water absorption and $\mathbf{c}$ percentage of thickness swell. Experimental design as described in Table 2, Study 1 and 2

amount of PdCe used as binder rose. The rate of increase differed for WdAh- and GyPl-supplemented FB. Up to $66.67 \%$ PdCe concentration (100 g of PdCe), tensile strength 
remained relatively comparable for WdAh-supplemented FB, but a significant rise was observed for $100 \%$ PdCe. The GyPl-supplemented FB increased by more than twofold beyond $33.33 \%$ PdCe but did not change significantly up to $100 \%$ PdCe concentration. As shown in Fig. 6a, the binder plays a very crucial role in the quality of FB produced. On the contrary, a significant high compressive strength was observed for $100 \% \mathrm{WdAh}$-supplemented FB. It implies that the use of WdAh increases the FB ductility largely. For the FB, achieving a good balance between the FB ductility and brittleness is very important. Increasing the amount of PdCe significantly reduced the compressive strength. A GyPl-supplemented FB had low compressive strength. However, a slight increase was observed as PdCe concentration increased up to $100 \%$ (Fig. 6b). Cement-bonded materials are known for their propensity to be brittle, notwithstanding

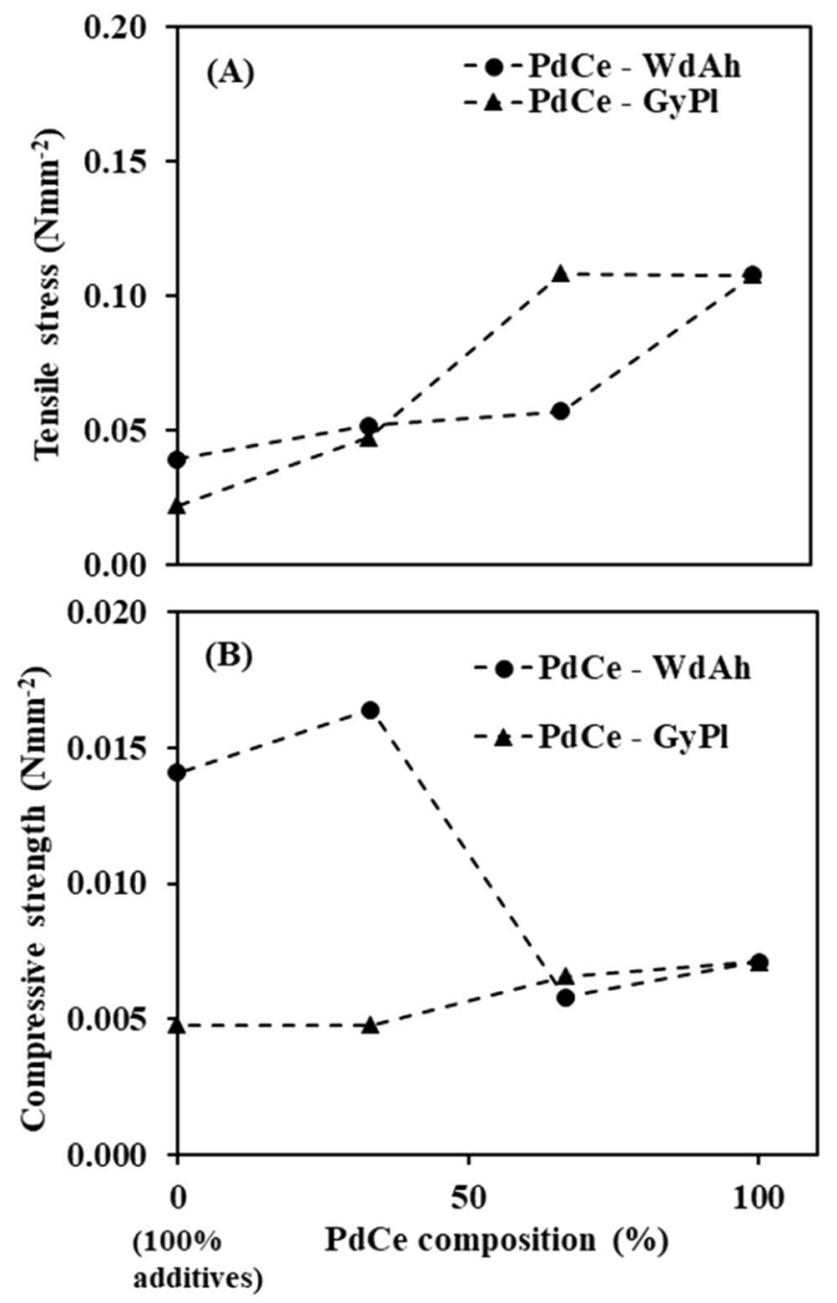

Fig. 6 Effect of mixed proportion of PdCe as a binder and WdAh/ $\mathrm{GyPl}$ as additives on the mechanical properties of a FB produced from equal amount of WaHy and WP. a Tensile stress, and b compressive strength. Experimental design as described in Table 2, Study 1 and 2 and the composites fibres present in the FB enhance the ductile properties under compressive forces. Achieving the right composite mix is essential to meet the ASTM standards based on selected investigated properties.

\section{Implication of non-cementitious additives on physical and mechanical properties}

The effects of non-cementitious additives were investigated on the properties of the FB produced. As shown in Fig. 7, only three conditions of composites mixtures were tested for the WdAh and GyPl. Irrespective of the mixing conditions, additives had no significant effect on the FB density. Densities were low $\left(<0.5 \mathrm{~g} \mathrm{~cm}^{-3}\right)$ and comparable with that observed for previous conditions. The thickness swell for GyPl as a sole additive was half the WdAh and mixed GyPl-WdAh. The reduced thickness swell may be due to harder core formed with less porosity. Again, the chemical composition of $\mathrm{GyPl}$, which produced fire-retardant properties, contributed to the surface chemistry of the FB produced. Notwithstanding, water absorptivity for GyPl was reduced by almost $3 \%$ compared to WdAh and bi-composites FB. The overall assessment of using non-cementitious materials as key binders resulted in FB with lowered desirable physical properties. The mechanical properties of the FB produced showed a decline in the compressive strength as the WdAh percentage composition decreased. Using only GyPl also resulted in 50\% reduction of the compressive strength. However, the tensile strength of the FB though

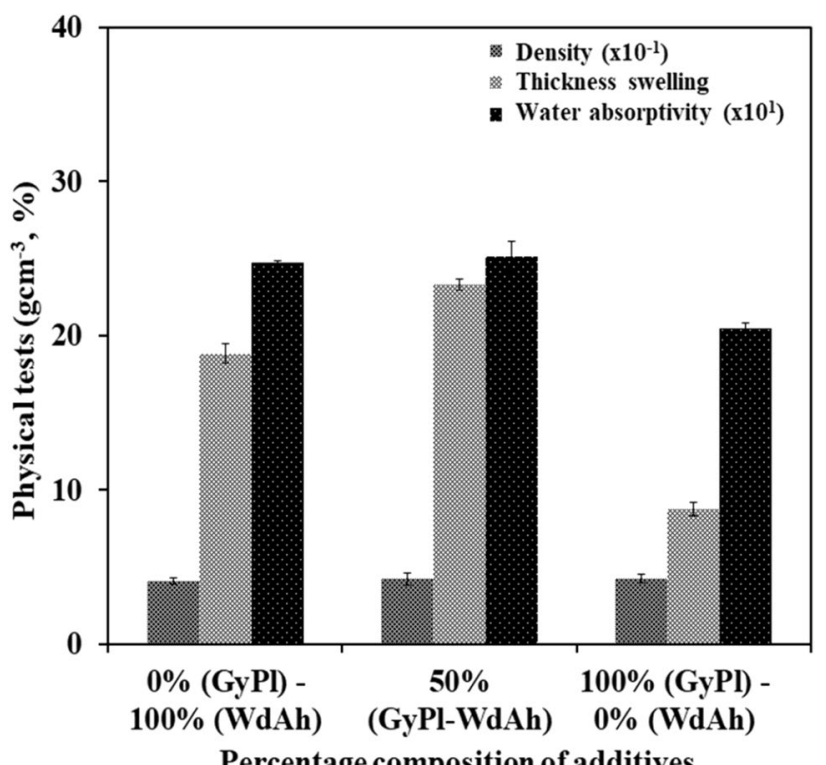

Fig. 7 Effect of mixed proportion of additives-WdAh and GyPl without a binder on the physical properties of a fibreboard produced from equal amount of WaHy and WP. Experimental design as described in Table 2, Study 3 


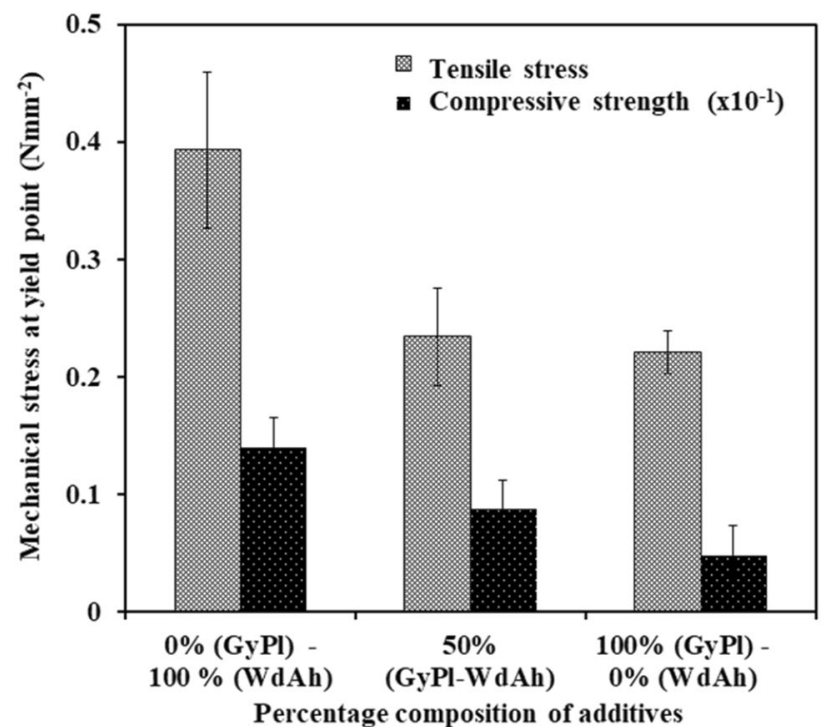

Fig. 8 Effect of mixed proportion of only additives-WdAh and $\mathrm{GyPl}$ on the mechanical properties of a FB produced from equal amount of WaHy and WP. Experimental design as described in Table 2, Study 3

higher for $100 \%$ WdAh, showed no significant difference for both combined composites and 100\% GyPl (Fig. 8). The higher tensile and compressive strength implied greater strength to withstand impacts when used for construction purposes.

\section{Physical observation and comparison with standards}

The entire FB produced gave good physical appearances with slight variance in colour. The WP had a whitish colour while the ones with higher WaHy have more pronounced brownish colour. FBs with properties within the acceptable ASTM D-1037 and ANSI A208.2 ranges are presented in Table 3. Cement-bonded FBs with $50 \mathrm{~g}$ of either WdAh or GyPl have the highest density with significantly low percentage thickness swelling. It implied that as a low mediumdensity FB, the FB was less susceptible to swelling and expansion if in contact with water for the first few hours. With closely packed core, insulation properties may be compromised. Another factor to be considered when evaluating the suitability of a panel product for building construction is its ability to hold nails, especially when they are subjected to a load. A nail-head pull through the test is commonly used to assess this property. In this test, a 2-inch $(5 \mathrm{~cm})$ nail was hammered into sample board, and the board was observed under the impact force. FB which withstood the impact force without breaking was considered to be passed. From the physical and mechanical tests carried out, samples were tested against the standard recommended benchmarks and

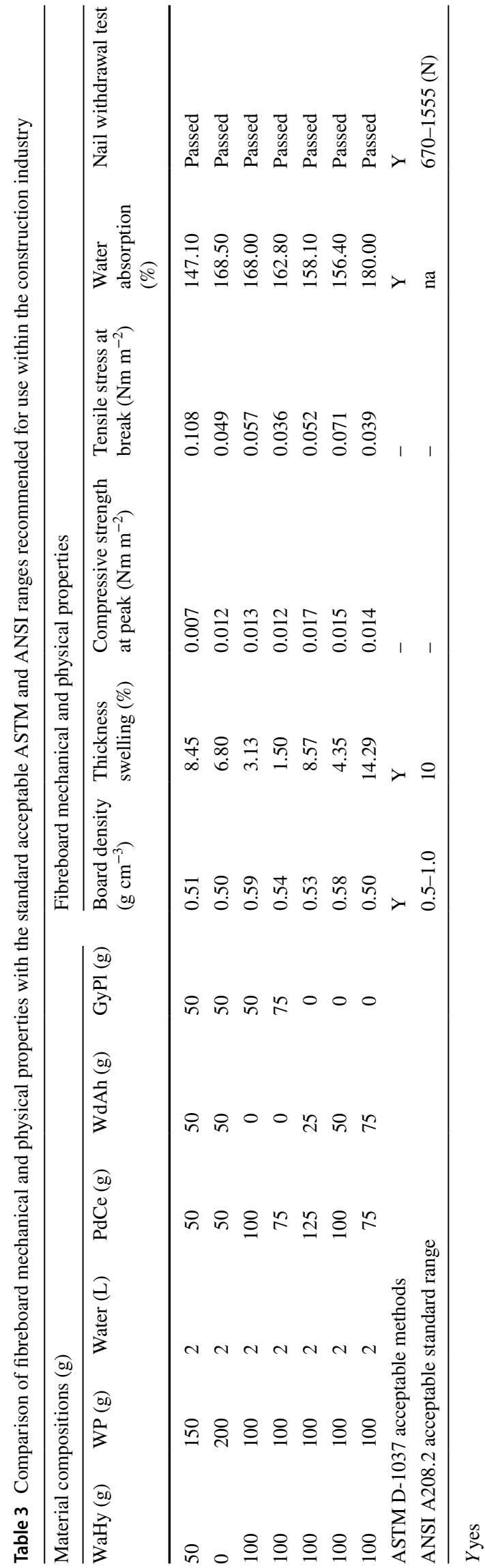


comparison shown in Table 3. In summary, with an equal proportion of WP and WaHy, using PdCe and WdAh mixed in the ratio 2:1 would result in FB that meets the standard requirement.

\section{Conclusions}

The result of this study showed that the production of bicomposite FB using WP and WaHy as the primary lignocellulosic fibres achieved good quality standards comparable to those available in the market. A cementitious-bonded FB with WdAh as the additive achieved improved quality compared to GyPl being used as an additive. Again, micronisation and hornification of the WP before use were believed to have improved the FB formation; this was, however, not tested with non-micronised WP in this study. Use of WdAh and GyPl as the sole binders resulted in FB with a reduced quality, hence discouraged. Also, a simple, low-cost prototype designed mixing and compacting processes was acceptable for this early study, but more studies regarding improvements and optimisation are proposed with better quality control measures in place for the mixing homogeneity and compaction pressure. Cement-bonded, bi-composite FBs can be produced using WP and WaHy with WdAh as an additive to improve the fire-retardant properties. Production of the eco-friendly FBs on a large scale would minimise the municipal solid waste load and ensure effective cost management of WaHy on the water bodies while it was being used for biosorption of toxic compound from the environment.

Acknowledgements This research did not receive any specific grant from funding agencies in the public, commercial, or not-for-profit sectors.

Open Access This article is distributed under the terms of the Creative Commons Attribution 4.0 International License (http://creativeco mmons.org/licenses/by/4.0/), which permits unrestricted use, distribution, and reproduction in any medium, provided you give appropriate credit to the original author(s) and the source, provide a link to the Creative Commons license, and indicate if changes were made.

\section{References}

1. Ormondroyd GA, Stefanowski B (2015) Fibreboards and their applications. Wood Compos 2015:91-102. https://doi. org/10.1016/B978-1-78242-454-3.00005-6

2. Karade SR (2010) Cement-bonded composites from lignocellulosic wastes. Constr Build Mater 24:1323-1330. https://doi. org/10.1016/j.conbuildmat.2010.02.003

3. Ardanuy M, Claramunt J, Dias R, Filho T (2015) Cellulosic fiber reinforced cement-based composites : a review of recent research. Constr Build Mater 79:115-128. https://doi.org/10.1016/j.conbu ildmat.2015.01.035
4. Ye XP, Julson J, Kuo M et al (2007) Properties of medium density fiberboards made from renewable biomass. Bioresour Technol 98:1077-1084. https://doi.org/10.1016/j.biortech.2006.04.022

5. Ali I, Jayaraman K, Bhattacharyya D (2014) Effects of resin and moisture content on the properties of medium density fibreboards made from kenaf bast fibres. Ind Crops Prod 52:191-198. https:// doi.org/10.1016/j.indcrop.2013.10.013

6. Ciannamea EM, Stefani PM, Ruseckaite RA (2010) Mediumdensity particleboards from modified rice husks and soybean protein concentrate-based adhesives. Bioresour Technol 101:818-825. https://doi.org/10.1016/j.biortech.2009.08.084

7. Bolenz S, Omran H, Gierschner K (1990) Treatments of water hyacinth tissue to obtain useful products. Biol Wastes 33:263274. https://doi.org/10.1016/0269-7483(90)90130-K

8. Aggarwal LK, Agrawal SP, Thapliyal PC, Karade SR (2008) Cement-bonded composite boards with arhar stalks. Cem Concr Compos 30:44-51. https://doi.org/10.1016/j.cemconcomp .2007 .07 .004

9. Ashori A, Tabarsa T, Sepahvand S (2012) Cement-bonded composite boards made from poplar strands. Constr Build Mater 26:131-134. https://doi.org/10.1016/j.conbuildmat.2011.06.001

10. Li X, Cai Z, Winandy JE et al (2010) Selected properties of particleboard panels manufactured from rice straws of different geometries. Bioresour Technol 101:4662-4666. https://doi. org/10.1016/j.biortech.2010.01.053

11. Neithalath N, Weiss J, Olek J (2004) Acoustic performance and damping behavior of cellulose-cement composites. Cem Concr Compos 26:359-370. https://doi.org/10.1016/S0958 -9465(03)00020-9

12. Singh M, Garg M (1994) Gypsum-based fibre-reinforced composites: an alternative to timber. Constr Build Mater 8:155-160. https://doi.org/10.1016/S0950-0618(09)90028-9

13. Nemli Ã (2006) Influences of some factors on the formaldehyde content of particleboard. Build Environ 41:770-774. https://doi. org/10.1016/j.buildenv.2005.03.016

14. Karina M, Onggo H, Syampurwadi A (2007) Physical and mechanical properties of natural fibers filled polypropylene composites and its recycle. J Biol Sci 7:393-396

15. Okino EYA, De Souza MR, Santana MAE et al (2004) Cementbonded wood particleboard with a mixture of eucalypt and rubberwood. Cem Concr Compos 26:729-734. https://doi. org/10.1016/S0958-9465(03)00061-1

16. Gopal B (1987) Water hyacinth control and possible uses. Aquat plant Stud I 1:1-10

17. Gunnarsson CC, Petersen CM (2007) Water hyacinths as a resource in agriculture and energy production: a literature review. Waste Manag 27:117-129. https://doi.org/10.1016/j. wasman.2005.12.011

18. Malik A (2007) Environmental challenge vis a vis opportunity: the case of water hyacinth. Environ Int 33:122-138. https://doi. org/10.1016/j.envint.2006.08.004

19. Ndimele PE, Kumolu-Johnson CA, Anetekhai MA (2011) The invasive aquatic macrophyte, water hyacinth \{Eichhornia crassipes(Mart.) Solm-Laubach: Pontedericeae\}: problem and prospects. Res J Environ Sci 5:509-520. https://doi. org/10.3923/rjes.2011.509.520

20. Aigbomian EP, Fan M (2013) Development of Wood-Crete building materials from sawdust and waste paper. Constr Build Mater 40:361-366. https://doi.org/10.1016/j.conbuildma t.2012.11.018

21. Valente M, Tirillò J, Quitadamo A (2015) Industrial paper recycling process : suitable micronization for additive polymer application. City Saf Energy J 2:145-152

22. Walter A, Silberberger S, Juárez MF-D et al (2016) Biomethane potential of industrial paper wastes and investigation of the 
methanogenic communities involved. Biotechnol Biofuels 9:21. https://doi.org/10.1186/s13068-016-0435-z

23. Argun H, Dao S (2016) Hydrogen gas production from waste peach pulp by dark fermentation and electrohydrolysis. Int $\mathbf{J}$ Hydrogen Energy 41:11568-11576. https://doi.org/10.1016/j. ijhydene.2015.11.170

24. Huang J, Dai H, Yan R, Wang P (2016) Butyric acid production from recycled waste paper by immobilized Clostridium tyrobutyricum in a fibrous-bed bioreactor. J Chem Technol Biotechnol 91:1048-1054. https://doi.org/10.1002/jctb.4680

25. Guan W, Shi S, Tu M, Lee YY (2016) Acetone-butanol-ethanol production from Kraft paper mill sludge by simultaneous saccharification and fermentation. Bioresour Technol 200:713-721. https://doi.org/10.1016/j.biortech.2015.10.102

26. Argun H, Onaran G (2016) Glucose and 5-hydroxymethylfurfural production from cellulosic waste by sequential alkaline and acid hydrolysis. Renew Energy 96:442-449. https://doi.org/10.1016/j. renene.2016.04.082

27. Ojo EO, Edomwonyi-Otu LC, Solomon BO (2017) Novel technique for micronisation of waste paper and implication for bioethanol production. Niger J Eng 24:73-80

28. Savastano H, Warden PG, Coutts RSP (2000) Brazilian waste fibres as reinforcement for cement-based composites. Cem Concr Compos 22:379-384. https://doi.org/10.1016/S0958 -9465(00)00034-2

29. Du Y, Yan N, Kortschot MT (2014) The use of ramie fibers as reinforcements in composites. Biofiber Reinf Compos Mater 2015:104-137. https://doi.org/10.1533/9781782421276.1.104

30. Claramunt J, Ardanuy M, García-Hortal JA, Filho RDT (2011) The hornification of vegetable fibers to improve the durability of cement mortar composites. Cem Concr Compos 33:586-595. https://doi.org/10.1016/j.cemconcomp.2011.03.003
31. Claramunt J, Ardanuy M, García-Hortal JA (2010) Effect of drying and rewetting cycles on the structure and physicochemical characteristics of softwood fibres for reinforcement of cementitious composites. Carbohydr Polym 79:200-205. https://doi. org/10.1016/j.carbpol.2009.07.057

32. Quintana G, Velásquez J, Betancourt S, Gañán P (2009) Binderless fiberboard from steam exploded banana bunch. Ind Crops Prod 29:60-66. https://doi.org/10.1016/j.indcrop.2008.04.007

33. Ferrando F, Salvado J (2003) Effects of kraft lignin addition in the production of binderless fiberboard from steam exploded Miscanthus sinensisMiscanthus sinensis. Ind Crops Prod 18:17-23. https://doi.org/10.1016/S0926-6690(03)00016-5

34. Arévalo R, Peijs T (2016) Composites: part A Binderless allcellulose fibreboard from microfibrillated lignocellulosic natural fibres. Compos Part A 83:38-46. https://doi.org/10.1016/j.compo sitesa.2015.11.027

35. Khorami M, Ganjian E (2013) The effect of limestone powder, silica fume and fibre content on flexural behaviour of cement composite reinforced by waste Kraft pulp. Constr Build Mater 46:142-149. https://doi.org/10.1016/j.conbuildmat.2013.03.099

36. Wang D, Sun XS (2002) Low density particleboard from wheat straw and corn pith. Ind Crops Prod 15:43-50

37. Mo X, Hu J, Sun XS, Ratto JA (2001) Compression and tensile strength of low-density straw-protein particleboard. Ind Crops Prod 14:1-9. https://doi.org/10.1016/S0926-6690(00)00083-2

Publisher's Note Springer Nature remains neutral with regard to jurisdictional claims in published maps and institutional affiliations. 